\title{
MEASURING CUSTOMER'S SATISFACTION ON BUS TRANSPORTATION
}

\author{
${ }^{1}$ Rabiul Islam, ${ }^{2}$ Mohammed S. Chowdhury, \\ ${ }^{1}$ Mohammad Sumann Sarker and ${ }^{1}$ Salauddin Ahmed \\ ${ }^{1}$ School of Economics, Finance and Banking, College of Business, \\ University Utara Malaysia, 06010 UUM, Sintok, Kedah, Malaysia \\ ${ }^{2}$ Department of Marketing and Management, Touro College, New York
}

Received 2014-04-09; Revised 2014-04-30; Accepted 2014-05-23

\begin{abstract}
The purpose of the study is to examine the factors measuring customers' satisfaction, especially the impact of service quality on customers' satisfaction in public transportation industry in the university town of Sintok located in Kedah province of Malaysia. In order to assess the relationships between service quality and customer satisfaction survey http://www.scientificjournals.org/journals2007/articles/1003.htmdata were collected from 300 Bus commuters. All hypotheses were tested using Pearson correlations, controlling for the background variables of gender, marital status, ethnicity and education. The results indicate that hypotheses 1 through 5 were supported. Using multiple regressions as a basis for causal paths, a model was developed that examined the influence of all five dimensions of service quality on customers' satisfaction. The model explained $26.9 \%$ of the variance which indicates that $26.9 \%$ of the changes in the dependent variable are explained by the independent variables. Altogether, independent variables explained $26.9 \%$ of the variations.
\end{abstract}

Keywords: Customer Satisfaction, Public Transportation, Service Quality, Environment, Service Dimension

\section{INTRODUCTION}

Satisfaction can be defined as an experience of fulfillment of an expected outcome. Satisfaction or dissatisfaction with a program or facilities is influenced by prior expectations regarding the level of quality (Sigala, 2004). Satisfaction depends on numerous factors and there is no dearth of literatures on this subject. To generate the factors leading customer satisfaction we look at some research studies done in this field. Studies conducted that customers want the best service quality and responses as well to what they want (Zheng and Jiaqing, 2007).

According to Anderson et al. (2007) which affects customers' satisfaction is the operation failures of the services such as delay of transportation. This creates bias to customers, resulting in dissatisfaction. Friendliness of the personnel especially bus driver behavior in relation to service frequency has an impact on customer satisfaction. Friendliness behavior of the bus driver can satisfy customers by developing better communication and knowledge of its customers' needs (Disney, 1998). As far as frequency is concerned, frequent services increase satisfaction and urban transportation patronage (Taylor et al., 2008). Additionally Andreassen (1995) claimed that customer (dis) satisfaction in public tran finally, the layout of the platform or the station, especially for buses. Reliability, convenience and responsiveness are also considered to be important in customer satisfaction (Cavana and Corbett, 2007). Consumer choices affect the perceived level of operation (for example, the length of the path and travel time and the number and length of service, frequency of bus services). Waiting time for long, failure to provide ge of Business, University Utara Malaysia, 06010 UUM, Sintok, Kedah, Malaysia 
information of occasional delays and lack of good waiting environment are other factors are other causes of customer dissatisfaction (Bielen and Demoulin, 2007).

Service is called the backbone of the industries ensuring the rising and development of the economies (Esteban et al., 2002). Lytle and Timmerman (2006) showed that service orientation is the path which adds value to the customer and creates satisfaction. It, also, gives a competitive advantage and leads to development and profitability.

Tran and Kleiner (2005) define public transportation (herein referred to as PT) as a conveyance that provides continuing general or special transportation to the public: Trolleys, busses, subways, rail and ferry boats. The authors, also, show that public transportation plays a significant role as it improves the quality of our day to day life by expediting traffic saves money and creates new jobs. In support of this argument we can cite the establishment of University Utara Malaysia in as an example the establishment of this university in Sintok followed by few other universities in its vicinity has had the greatest impact on the economy, particularly on the population of Sintok. Additionally it led to the rapid development of economic relationship between Sintok and other adjacent areas such as Changlun, Jitra and Alor Star. Existence of communication systems such as roads, followed by the existence of transport infrastructure has opened up opportunities for companies that provide transportation, especially bus. Bus services in Sintok and its surrounding areas exist to facilitate university student's movement in and out of campuses.

As reported by the commuters, the Bus services provided by High Bay Racking (HBR) in this region are engulfed with numerous problems such as waiting for a long time for the bus services (both public and university transportation), higher rate of bus fare for smaller distances compared to greater distances. In addition the quality of the bus services (bus conditions, punctuality and driver's norms and conduct, insufficient schedule of buses, less number of buses). All these suggest that the quality of the bus services has deteriorated and the customers' satisfaction has decreased and in some cases the scenario is even worst (lack of air condition in the buses). These prevailing situations, therefore, call for greater quality of bus services and enhanced satisfaction of passengers, more bus services and link to far greater number of destinations. Bus transportation is one of the most important among the public. The quality of bus services should be given attention by the company and it is the main topic of this study. This is because customer satisfaction is a highly profitable strategy for the company itself. Based on research that has been made, the quality of bus services is the main thing has been the area of interest in marketing research.

Quality is defined as adherence to customer specifications (Parasuraman et al., 1988) which sought to meet the criteria that customers want. Measuring the quality of service is important to ensure that customers continue to visit the business for repeat purchases. In the transport business principles apply. If the customer is satisfied with the performance of the bus, the customer will return and use the same bus. Also likely customers will continue to use the bus service which she feels will satisfy their needs.

Parasuraman et al. (1988) suggest using the 10 construction quality of service, but was reduced to 5 , comprising:

- Tangibles: Tangible equipment required to render services and the presentations of service staff

- Reliability: The actual implementation, in a timely manner, of the committed services

- Responsiveness: The willingness of service personnel to offer speedy services

- Assurance: Professional knowledge, good manners and trustworthiness of service staff

- Empathy: The provision of convenient and considerate services to customers, catering to their specific needs

There have been plenty of research studies in the field of customer satisfaction in Public Transportation but we do not know of any study done in this area related to bus services in Sintok area of Kedah Province in Malaysia. The present study is aimed at filling that gap in the body of literature.

Additionally, a research like this is essential to assess and improve service delivery and design, because it will provide management with data that they can use in making inferences about the customers (Wilson et al., 2008). Thus the results of this study should be proved useful for academics; business in the field of marketing and management researchers of customer satisfaction and service quality especially in service sector organizations.

The researchers plan to study the impact of service quality on customer satisfaction in public transport sector of Sintok city in the province of Kedah, Malaysia. In the literature, there are ranges of sources, which address the factors for measuring customer satisfaction in the transportation industry. To date there is lack of research in this field in this university town in Malaysia's Kedah State. This university town 
where few universities are located is expanding literally to accommodate its nascent Bus services and create space for an expected influx of commuters in and out of university campuses.

However, it is essential that this region develops a long term transportation blueprint for Bus services for any further progress in transportation ventures. This region of Malaysia has everything it needs to develop a customer satisfaction driven Bus services-friendly people, safety and a current major infrastructure development project. In term of technology and cultural heritage it offers the best of both worlds, but if it is to succeed then all the pieces need to be in place.

This study discusses the service quality factors for measuring customer satisfaction that affect the bus services in this area provided by HBR. It examines and explores the service quality factors that will affect customer satisfaction for causing greater productivity and higher performance of this industry.

\section{MATERIALS AND METHODS}

\subsection{Theoretical Framework and Hypotheses Generation}

This study is based on research about service quality dimensions and their relationships to customer satisfaction. Public transport should become part of a solution for sustainable transport in the future. However, in order to keep and attract more passengers, public transport must to have high service quality to satisfy and fulfill more wide range of different customer's needs (Anable, 2005). Quality is defined as "adherence to customer specifications" (Parasuraman et al., 1988) which sought to meet the criteria that customers want. Satisfaction or dissatisfaction with a program or facilities is influenced by prior expectations regarding the level of quality (Ekinci, 2004).

The criteria which affect the overall satisfaction are, therefore, based in the literature review and they can be specified after an interaction between the analyst and the concerning company (Mihelis et al., 2001). More specifically, after an interaction with the administration of HBR Bus services in Sintok it has been decided that the research will take place and will be analyzed according to the following criteria:

- Services: Include the price of ticket, the service of personnel (behavior of bus driver), service inside the bus (comfort, cleanliness and air condition), service outside the bus (layout of bus stops) and route safety
- Access: Consists of the access in bus stops and access in tickets

- Availability: This means coverage of network, connectivity of lines, route frequency, route working hours, bus stop frequency

- Time: This denotes route precise, route waiting time and route duration

- Environment: This limits to bus aesthetics and bus pollution

The theory is that all these five components depicted in the diagram as independent variables directly affect customer satisfaction. The figure posits that there is an interrelationship between these five service quality dimensions (service, access, availability, time and environment) customer satisfaction.

\subsection{Research Design}

This study employed a survey research design to collect data from the participants to investigate relationship among five components of service quality and customer satisfaction. The research is quantitative in nature. Quantitative data allows the researchers to present data in descriptive form and also to determine possible relationships between two or more variables. Quantitative research involving correlations describes the degree in which two or more variables are related (Fraenkel and Wallen, 2003). The independent variable used in this study is overall satisfaction with HBR bus transport service. Independent variables are specific service quality attributes which consist of service given, access, availability, time and environment. These are the five dimensions of service quality deduced from Service quality literatures.

\subsection{Survey Instrument}

This research was conducted through the questionnaire to find out the relationship between quality of services and customers satisfaction towards bus services provided by HBR. For that, this survey followed through the questionnaire method. The questionnaires were distributed to all categories of students that were met in the class, library, office, mosque, cyber cafe and so on at main Campus of UUM.

The dimensions of the service quality proposed in our model used for measuring service quality following SERVQUAL model (Parasuraman et al., 1988) are efficiently exploited when we carry out surveys, since it deals with expectations and perceptions of individuals about services offered by retailer such as HBR. For us to 
know how customers perceive service quality, it is appropriate to use self-completed questionnaires which give the respondents a chance to independently and anonymously give answers that reflect their expectations and perceptions. Our questionnaire is developed in accordance with the SERVQUAL model and thus, this makes it objective and not bias.

In business research, it is hardly possible to control or manipulate a variable which is a good reason to count on social survey. Variables like gender, age and social background are given and cannot be amended (Bryman and Bell, 2007). This makes it totally unfeasible to use the experimental design and we resort to the social survey.

To structure the questionnaire we used the method of Grigoroudis et al. (1997) since we assume that it is simple, short and reliable and provides convenience in collecting information. A questionnaire is defined as a form that people fill out used to obtain demographic and views and interests of those questioned. We used 5point Likert scale in which the respondents rated the degree of his or her agreement/disagreement beginning from $1=$ unsatisfied, $2=$ little satisfied, $3=$ satisfied, $4=$ very satisfied and ending with $5=$ absolutely satisfied Passengers were asked to assess their satisfaction level according to the described set of 5 criteria (Fig. 1) each of which were divided in 17 sub criteria.

\subsection{Data Collection}

Primary and secondary data are used in this research. The primary data defined as the data collected first hand for subsequent analysis to find solutions to the problem research. The primary data were obtained from a questionnaire survey while the secondary data refer to information gathered by someone other than the researcher conducting the current study (Sekaran and Bougie, 2009). The secondary data were obtained from books, brochures and pamphlets, company publications, documents government publication indexes, newspaper, periodicals and journals, internet web sites.

To access the respondents of this study for data collection, the questionnaires were distributed to the respondents by handed personally. Confidentiality was assured by encouraging the respondent to return back the questionnaire directly.

\subsection{Population and Sample}

Population refers to the entire group of people, events, or things of interest that the researcher wishes to investigate and the sample also is a subset of the population (Sekaran and Bougie, 2009). In particularly, the research subject comprised the buses provided by HBR in the city of Sintok and its vicinity as every day almost 15,000 people (mostly UUM students) transfer in a price ticket from 0,45 cent to 1,45 cent with a cover access to the city of Sintok and the suburbs around the city. It, also, has in its possession 89 new buses which are considered one of the most modern buses in Malaysia as they are environmentally friendly with a synchronous design.

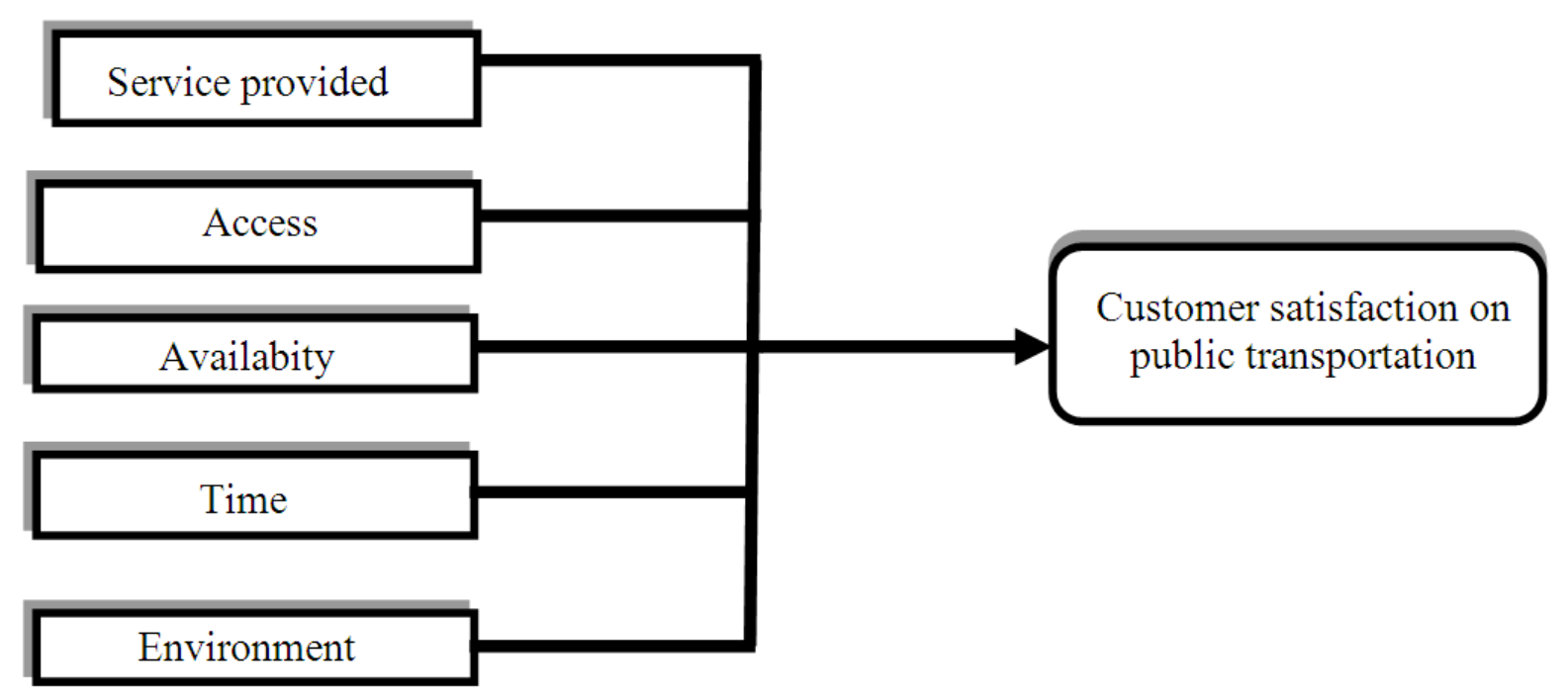

Fig. 1. Theoretical framework 
University Utara Malaysia (UUM) is one of the few universities in Malaysia that provides full on campus accommodation for all its undergraduate students. There are fourteen residential colleges scattered around 1061 hectares of land that house more than twenty thousand fulltime students. Students depend on good transportation to go outside the campus such as Changlun, Jitra and Alor star and so on. This research is about customer's satisfaction through the HBR bus services and UUM students are population and the sample of this research. Since the focus of research is exploratory, convenience sampling is done for the sampling purposes, as this method is considered as easy, fastest and most efficient way to collect the information that were needed (Sekaran, 2000) 300 questionnaires were distributed. Only 278 students filled up the questionnaire and were used for this study. Of these 278 students, 184 students $(66 \%)$ were female.

\subsection{Data Analysis}

After the data were collected, data were analyzed using correlation in order to establish relationship between five criteria selected for the study (service, access, availability, time and the environment) and customer satisfaction. All hypotheses were tested by the coefficient of correlation measure and regression analysis. Hypotheses testing were done to analyze direct effects of independent variables on customer satisfaction, controlling demographic variables. For demographic variables, frequency tables were used for the purpose of analysis.

\subsection{Regression Model}

$$
Y=a+b_{1} X_{1}+b_{2} X_{2}+b_{3} X_{3}+b_{4} X_{4}+b_{5} X_{5}+\mu
$$

Where:

$\mathrm{Y}=$ The value of the Dependent variable (customer satisfaction), what is being predicted or explained

$\mathrm{A}=($ Alpha) the Constant or intercept

$b_{1}=$ The Slope (Beta coefficient) for $X_{1}$

$b_{2}=$ The Slope (Beta coefficient) for $X_{2}$

$b_{3}=$ The Slope (Beta coefficient) for $X_{3}$

$\mathrm{b}_{4}=$ The slope (Beta coefficient) for $\mathrm{X}_{4}$

$b_{5}=$ The slope (Beta coefficient) for $X_{5}$

$\mathrm{X}_{1}=$ First independent variable (service) that is explaining the variance in $\mathrm{Y}$ (customer satisfaction)

$\mathrm{X}_{2}=$ Second independent variable (access) that is explaining the variance in $\mathrm{Y}$ (customer satisfaction)

$\mathrm{X}_{3}=$ Third independent variable (availability) that is explaining the variance in $\mathrm{Y}$ (customer satisfaction)
$\mathrm{X}_{4}=$ the fourth independent variable (time) that is explaining the variance in $\mathrm{Y}$ (customer satisfaction) $\mathrm{X}_{5}=$ Fifth independent variable (environment) that is explaining the variance in $\mathrm{Y}$ (customer satisfaction)

The above regression model consists of a function describing how response variable is related to one or other explanatory variables, how changes in one or more variables will change the value of another. In other words the model was employed to look at the effects of $\mathrm{X}_{1}$ (service), $\mathrm{X}_{2}$ (access), $\mathrm{X}_{3}$ (availability), $\mathrm{X}_{4}$ (time) and $\mathrm{X}_{5}$ (environment) on customer satisfaction, controlling demographic variables.

\section{RESULTS}

The finding is divided into sections. The first section deals with descriptive statistics of the students and the second section consists of correlation and regression analysis for hypotheses testing. Descriptive statistics are used to explore the data collected and to summarize and describe those data (Coakes and Steed, 2007). Descriptive statistics may be particularly useful to make some general observations about the data collected (for example, demographic data). The demographic information in this research is ethnic groups, gender, age and education. All the population under study has commuting experience from the Bus service provided by HBR.

\subsection{Demographic Factors of Commuters}

Biographical information of commuters was obtained including their age group classifications, marital status and experience in commuting by Bus provided by HBR in Table 1.

Table 1 indicates that in ethnic groups Malaysian comprises almost one-third of the population under study. This means that fewer Malaysians commute by Bus in this city. It is quite obvious since they possess or can afford to possess their transportation like cars, mini vans and bikes. If you travel around the city and its adjacent sub-urbanizations, you will notice the young men and women are riding on the bikes to commute in and out of their dwelling places. The other ethnic groups use Bus service as their only means of transportation. Two reasons account for this: (a) These are full time students and cannot afford own transportation (b) they are away from home and hence have no desire for having their own transportation. Most are in the age of 25 and 35 and support the contention that they are not prone to have their own transportation since they are totally dependent on their parents' income that is from low income countries. 
Table 1. Demographic factors of commuters

\begin{tabular}{lll}
\hline Demographic factors & Frequency & $(\%)$ \\
\hline Ethnic commuters & & \\
Malaysian & 90 & 32 \\
African & 50 & 18 \\
Asian & 96 & 35 \\
Mid-eastern & 42 & 15 \\
Education: (enrolled in) & & \\
Bachelor & 108 & 38 \\
Master & 80 & 28 \\
Ph. D & 40 & 14 \\
D.B.A & 58 & 20 \\
Age & & \\
25 or less & 140 & 51 \\
26-30 & 45 & 17 \\
31-35 & 35 & 14 \\
36-40 & 30 & 12 \\
41 and more & 18 & 6 \\
Gender & & \\
Male & 170 & - \\
Female & 108 & - \\
\hline
\end{tabular}

Correlation is significant at the 0.01 level (2-tailed)

By analyzing the data gathered from question the questionnaire, the following results were obtained:

- The first services (such as the price of ticket, behavior of bus driver service inside and outside the bus (comfort, cleanliness and air condition, layout of bus stops and route safety) has the highest response $(95.8 \%)$ as factors measuring customer satisfaction

- The second satisfying factor is access to bus stops and tickets with a response of $90.6 \%$ )

Time (route waiting time and route duration) was the third most important factor in measuring customer satisfaction with a response rate of $87.4 \%$ ) while the availability (such as bus stop frequency) and the environment (such as bus aesthetics) ranked fourth $(85.8 \%)$ and fifth $(83.7 \%)$.

\subsection{Hypotheses Testing}

\section{Hypothesis 1}

$\mathrm{H}_{01}$ : There is no significant relationship between customer satisfaction and the service provided by HBR Bus services.

$\mathrm{H}_{\mathrm{a} 1}$ : There is a significant relationship between customer satisfaction and the service provided by HBR Bus services.

Since both variables are interval. Person correlation test was conducted and results are depicted in Table 2.
Table 2. Correlation between customer satisfaction and the service provided

\begin{tabular}{llrr}
\hline & & Services & $\begin{array}{c}\text { Customer } \\
\text { satisfaction }\end{array}$ \\
\hline Services & Pearson correlation & 1.000 & $826^{* *}$ \\
& Sig. 2-tailed & & 0.000 \\
& $\mathrm{~N}$ & 278.000 & 278.000 \\
Customer & Pearson correlation & 0.826 & 1.000 \\
Satisfaction & Sig. 2-tailed & 0.000 & \\
& N & 278.000 & 278.000 \\
\hline
\end{tabular}

Correlation is significant at the 0.01 level (2-tailed)

The null is rejected and alternate hypothesis is accepted which means there is a positive and significant correlation between services and customer satisfaction.

\section{Hypothesis 2}

$\mathrm{H}_{02}$ : There is no significant relationship between access and customer satisfaction.

$\mathrm{H}_{\mathrm{a} 2}$ : There is a significant relationship between access to service by HBR and customer satisfaction.

The result shows that there is a positive and significant correlation between access dimensions and customer satisfaction $\left(\mathrm{r}=0.65^{* *}\right)$, as depicted in Table 3 .

\section{Hypothesis 3}

$\mathrm{H}_{03}$ : There is no significant relationship between availability dimensions and customer satisfaction.

$\mathrm{H}_{\mathrm{a} 3}$ : There is a significant relationship between availability dimensions and customer satisfaction.

Table 4 depict that availability dimensions and customer satisfaction are significantly correlated $(r=0.56)$. Null is rejected and alternate hypothesis is accepted.

\section{Hypothesis 4}

$\mathrm{H}_{04}$ : There is no significant relationship between time and customer satisfaction

$\mathrm{H}_{\mathrm{a} 4}$ : There is a significant relationship between time and customer satisfaction

Null hypothesis is rejected while alternate hypothesis is accepted denoting the significant and positive correlation between time and customer satisfaction $(r=$ $0.690^{* *}$ ), as is evidenced from Table 5.

\section{Hypothesis 5}

$\mathrm{H}_{05}$ : There is no significant relationship between the Bus environment and customer satisfaction

$\mathrm{H}_{\mathrm{a} 5}$ : There is a significant relationship between the Bus environment and customer satisfaction.

This hypothesis also is accepted signifying the significant and positive correlation between environment dimensions and customer satisfaction in Table 6. 
Table 3. Correlation between customer satisfaction and access

\begin{tabular}{llrc}
\hline & & Services & $\begin{array}{l}\text { Customer } \\
\text { satisfaction }\end{array}$ \\
\hline Access & Pearson correlation & 1.000 & $0.650^{* *}$ \\
& Sig. 2-tailed & & 0.000 \\
& N & 278.000 & 278.000 \\
Customer & Pearson correlation & 0.826 & 1.000 \\
Satisfaction & Sig. 2-tailed & 0.000 & \\
& N & 278.000 & 278.000 \\
\hline
\end{tabular}

Correlation is significant at the 0.01 level (2-tailed)

Table 4. Correlation between availability and customer satisfaction

\begin{tabular}{llcc}
\hline & & Services & $\begin{array}{c}\text { Customer } \\
\text { satisfaction }\end{array}$ \\
\hline Availability & Pearson correlation & 1.000 & $0.560^{* *}$ \\
& Sig. 2-tailed & & 0.000 \\
& N & 278.000 & 278.000 \\
Customer & Pearson correlation & 0.826 & 1.000 \\
Satisfaction & Sig. 2-tailed & 0.000 & \\
& N & 278.000 & 278.000 \\
\hline
\end{tabular}

Correlation is significant at the 0.01 level (2-tailed)

Table 5. Correlation between time and customer satisfaction

\begin{tabular}{llrl}
\hline & & Services & $\begin{array}{l}\text { Customer } \\
\text { satisfaction }\end{array}$ \\
\hline Time & Pearson correlation & 1.000 & $0.690^{* *}$ \\
& Sig. 2-tailed & & 0.000 \\
& N & 278.000 & 0,278 \\
Customer & Pearson correlation & 0.826 & 1 \\
Satisfaction & Sig. 2-tailed & 0.000 & \\
& N & 278.000 & 278 \\
\hline
\end{tabular}

Correlation is significant at the 0.01 level (2-tailed)C

Table 6. Correlation between environment and customer satisfaction

\begin{tabular}{llrc}
\hline \multicolumn{2}{c}{ Satisfaction } & Services & $\begin{array}{l}\text { Customer } \\
\text { satisfaction }\end{array}$ \\
\hline Environment & Pearson correlation & 1.000 & $0.661^{* *}$ \\
& Sig. 2-tailed & & 0.000 \\
& N & 278.000 & 278.000 \\
Customer & Pearson correlation & 0.826 & 1.000 \\
Satisfaction & Sig. 2-tailed & 0.000 & \\
& N & 278.000 & 278.000 \\
\hline
\end{tabular}

Correlation is significant at the 0.01 level (2-tailed)

\section{DISCUSSION}

\subsection{Regression Analysis}

We used the regression model to look at the effects of $\mathrm{X}_{1}$ (service), $\mathrm{X}_{2}$ (access), $\mathrm{X}_{3}$ (availability), $\mathrm{X}_{4}$ (time) and $\mathrm{X}_{5}$ (environment) on customer satisfaction, controlling demographic variables. If there is a relationship, using the information in the independent variables will improve our accuracy in predicting values for the dependent variable.
Table 7. All variables on customer satisfaction

\begin{tabular}{lllll}
\hline Model & $(\%)$ & Beta & T- test & Significance (\%) \\
\hline Constant & & - & 12.305 & 0.000 \\
Service & & 0.744 & 3.048 & 0.000 \\
Access & & 0.498 & 2.042 & 0.440 \\
Availability & & 0.581 & 2.761 & 0.003 \\
Time & & 0.469 & 2.121 & 0.002 \\
Environment & & 0.681 & 2.832 & 0.000 \\
Adjusted R square & 26.9 & & & \\
F value & 10.6 & & & \\
Significance & 0.000 & & & \\
\hline
\end{tabular}

As seen from Table 7, all variables have influenced customer satisfaction positively, as evidenced by highest $\mathrm{T}$ and Beta score. Adjusted R square for this model is $26.9 \%$ which indicates that $26.9 \%$ of the changes in the dependent variable are explained by the independent variables. Altogether, independent variables explained $26.9 \%$ of the variations.

\section{CONCLUSION}

To summarize, the present paper tried to reveal the important factors measuring customer satisfaction in Bus transportation services provided by HBR in the city of Sintok located at the province of Kedah, Malaysia. Findings indicate that satisfaction in customers varies in line with the service dimensions which affect total satisfaction. More precisely, the results indicated that customers present a moderate to strong level of satisfaction along the line of service dimensions. The sub criteria "route safety", "service of personnel", "service inside the bus" comprises the strong points of the company. To summarize, the overall result show that service quality attributes influences overall customer satisfaction in using public bus transport. High quality public bus transport not only keep customer to continue using public bus transport to fulfill their travel demand but also attract potential customer. The examination of the literature provide some interested results: Behavior of personnel and specifically behavior of bus driver, frequency of services, reliability of services as well as time and particularly waiting time seemed to be the most crucial factors affecting customer satisfaction within other.

These lead to the conclusion that HBR, to continue its satisfactory bus services for greater productivity and enhanced performance, must give due importance on these factors.

\section{REFERENCES}

Anable, J., 2005. Complacent car addicts' or 'aspiring environmentalists'? Identifying travel behaviour segments using attitude theory. Transport Policy, 12: 65-78. DOI: 10.1016/j.tranpol.2004.11.004 
Anderson, W.S., L.S. Baggett and S.K. Widener, 2007. The impact of service operations failures on customer satisfaction: Evidence on how failures and their source affect what matters to customers. Manufactur. Service Operat. Manage., 11: 52-69. DOI: $10.1287 / \mathrm{msom} .1070 .0193$

Andreassen, T.W., 1995. (Dis) satisfaction with public services: The case of public transportation. J. Services Market., 9: 30-41. DOI: 10.1108/08876049510100290

Bielen, F. and N. Demoulin, 2007. Waiting time influence on the satisfaction-loyalty relationship in services. Manage. Service Quality, 17: 174-193. DOI: $10.1108 / 09604520710735182$

Bryman, A. and E. Bell, 2007. Business Research Methods. 2nd Edn., Oxford University Press, Oxford.

Cavana, R.Y. and L.M. Corbett, 2007. Developing zones of tolerance for managing passenger rail service quality. Int. J. Quality Reliability Manage., 24: 7-31. DOI: $10.1108 / 02656710710720303$

Coakes, S.J. and L. Steed, 2007. SPSS Version 14.0 for Windows: Analysis without Anguish: Wiley.

Disney, J., 1998. Competing through quality in transport services. Manag. Service Quality, 8: 112-118. DOI: 10.1108/09604529810206918

Ekinci, Y., 2004. An investigation of the determinants of customer satisfaction. Tour Anal., 8: 197-203.

Esteban, A., N.A. Milla, A. Molina and D. MartinConsuegra, 2002. Market orientation in service: A review and analysis. Eur. J. Market., 36: 1003-1021. DOI: 10.1108/03090560210437307

Fraenkel, J. and N. Wallen, 2003. How to Design and Evaluate Research in Education. 1st Edn., McGrawHill, New York.

Grigoroudis, E., Y. Siskos and O. Saurais, 1997. Mia polikritiria prosegkisi gia tin axiologisi tis ikanopioisis ton pelaton, 11o Ethniko Synedrio Ellinikis Etairias Epichirisiakon Erevnon me thema "Diachirisi Poron kai Sistimaton gia viosimi anaptixi", Athens.
Lytle, S.R. and E.J. Timmerman, 2006. Service orientation and performance: An organizational perspective. J. Services Market., 20: 136-47. DOI: 10.1108/08876040610657066

Mihelis, A., E. Grigoroudis, Y. Siskos, Y. Politis and Y. Malandrakis, 2001. Customer satisfaction measurement in the private bank sector. Eur. J. Operat. Res., 130: 347-360. DOI: 10.1016/S03772217(00)00036-9

Parasuraman, A., V.A. Zeithaml and L.L. Berry, 1988. SERVQUAL: A multiple-item scale for measuring consumer perceptions of service quality. J. Retail., 64: $12-40$.

Sekaran, U. 2000. Research Methods for Business. 1st Edn., John Wiley and Sons, Inc., New York.

Sekaran, U. and R. Bougie, 2009. Research Methods for Business: A Skill Building Approach. 5th Edn., John Willey and Sons Ltd., Chichester, ISBN-10: 0470744790, pp: 488.

Sigala, M., 2004. The ASP-qual model: Measuring ASP service quality in Greece. Manag. Service Q., 14: 103-14. DOI: 10.1108/09604520410513703

Taylor, B.D., D. Miller, H. Iseki and C. Fink, 2008. Nature and/or nurture? Analyzing the determinants of transit ridership across US urbanized areas. Transport. Res., 43: 60-77. DOI: 10.1016/j.tra.2008.06.007

Tran, T. and H.B. Kleiner, 2005. Managing for excellence in public transportation. Manage. Res. News, 28: 154-63. DOI: 10.1108/01409170510785345

Wilson, A., V.A. Zeithaml, M.J. Bitner and D.D. Gremler, 2008. Services Marketing. 1st Edn., McGraw-Hill Education.

Zheng, L. and W. Jiaqing, 2007. summary of the application effect of bus rapid transit at Beijing South-Centre corridor of China. J. Transport. Syst. Eng. Inform. Technol., 7: 137-142. DOI: 10.1016/S1570-6672(07)60034-8 